\title{
Introduction to "A SEA OF MICROBES" special Issue
} BY LITA M. PROCTOR AND DAVID M. KARL

IN 1688, AFTER SEEING a copy of Robert Hooke's Micrographia, Antony van Leuwenhoek, a Dutchman who worked as a fabric merchant, surveyor, and wine assessor, was inspired to take up lens grinding to observe that which could not be seen by the naked eye. Among other things, he observed bacteria and protists from seawater and other natural habitats. Direct observation of microbes from the marine environment would not be perfected for another 300 years until Hobbie et al. (1977) provided a method for the quantitative estimation of bacteria in the sea. This
Until direct enumeration of marine bacteria, it was thought that bacteria were an inconsequential part of the ocean's food web. This belief was based on several ideas. Attempts to culture marine bacteria yielded few or no colonies, suggesting that bacterial densities in the sea were low. In addition, the general perception of bacteria was as decomposers-the "garbage collectors of the sea"-and hence of limited distribution. Finally, early models would not balance if a "bacterial box" was included, so these models tended to use linear phytoplankton-zooplankton-fish carbon transfer

\section{Until direct enumeration of marine}

\section{bacteria, it was thought that bacteria}

\author{
were an inconsequential part of
}

the ocean's food web... Imagine overlooking

\section{$50 \%$ of the total marine biomass and} then suddenly discovering it!

special issue of Oceanography on "A Sea of Microbes" captures the extraordinary and unimagined advances that have occurred in the few short years since that paper was published.

Why an issue on marine microbes? equations. There was no welcome mat for bacteria in the ocean.

Based on direct observation, the realization that there are $10^{6}$ bacteria $/ \mathrm{ml}$ of seawater (or ca. $5 \times 10^{6} /$ teaspoon) created a revolution in marine micro- bial ecology. Imagine overlooking 50\% of the total marine biomass and then suddenly discovering it! In rapid succession, we recognized the central role of bacteria (Pomeroy et al., page 28), protists (Sherr et al., page 130), archaea (DeLong, page 124), and viruses (Breitbart et al., page 135) in the ocean. We learned that fully half of the worldwide primary production occurs in the sea (Kolber, page 79), the bulk of which is microbial. Acting as the "lungs of the planet," the ocean is a major site of respiration (Carlson et al., page 89) and so plays a crucial role in the global carbon cycle. We now know that without microbes, nutrients, and metals (Ward et al., page 101; Dyhrman et al., page 110; Sievert et al., page 117) would not be regenerated and therefore the ocean's

LITA M. PROCTOR (Iproctor@pmc.ucsc. edu) is Associate Research Scientist, University of California, Santa Cruz, CA, USA, and currently Program Director, Molecular and Cellular Biosciences, Directorate of Biosciences, National Science Foundation, Arlington, VA, USA. DAVID M. KARL is Professor, Department of Oceanography, University of Hawaii, Honolulu, HI, USA. Opinions, findings, and conclusions or recommendations expressed in this paper are those of the authors and do not necessarily reflect the views of the NSF. 
productivity and the food web that depends on it would come to a grinding halt. We discovered that microbes are found throughout the world's ocean as integral members of ecosystems, from living out of the sea.

But oceanographers have always been troubled by how to sample and study the ocean. The ocean is vast. Even within a gyre, sampling strategies can be prob-

\section{[Microbial oceanography] is fascinating, not}

only because it is the study of that

\section{which cannot be seen with the naked eye}

but also because it is the study

of organisms that are fundamental to the

\section{functioning and health of the oceans.}

ice-bound polar regions (Hollibaugh et al., page 140) to tropical coral reefs (Rosenberg et al., page 146). We revisited the question of culturability and recognized that by mimicking natural conditions, many marine bacteria could be cultured (Giovannoni et al., page 62). This discovery has opened the door to many laboratory and model organism studies that were not possible before.

Modern genomic (Moran and Armbrust, page 47) and metagonomic (Edwards and Dinsdale, page 56) studies are beginning to reveal that marine microbes are not just bacteria or algae that happen to live in the sea but are highly adapted organisms that have evolved to make a lematic. Further, the ocean is a dynamic environment, and few opportunities are available to observe it on a 24-hour, 7-day-a-week, 12-months-a-year basis, which will be necessary if we ever hope to understand the impact of climate variability on marine microbial processes. In the end, we hope to learn whether the ocean and its microbial inhabitants are predictable (Cullen et al., page 34). To address these problems, in addition to modeling approaches (Hood et al., page 155), oceanographers have adopted satellites and, more recently, remotely operated instruments (Paul et al., page 70) to track oceanic phenomena. Kirchman and Pedrós-Alió (page 166) use the history of the field to look to its future, which promises to be exciting.

Indeed, why not an issue on marine microbes? This field is fascinating, not only because it is the study of that which cannot be seen with the naked eye but also because it is the study of organisms that are fundamental to the functioning and health of the oceans. This issue describes the growth and excitement of this young field, which we hope to convey to Oceanography's readership.

\section{ACKNOWLEDGEMENTS}

We warmly thank all of our colleagues who responded with great enthusiasm when we first proposed this special issue. They often worked under tremendous time constraints and sometimes confusing direction. We also would like to thank Ellen Kappel and the rest of the Oceanography staff for working closely with us to produce an accurate and attractive issue.

This issue received generous support from the Gordon and Betty Moore Foundation, the Agouron Institute, and the National Science Foundation (EF-0424599). 局

\section{REFERENCE}

Hobbie, J.E., R.J. Daley, and S. Jasper. 1977. Use of Nuclepore filters for counting bacteria by fluorescence microscopy. Applied and Environmental Microbiology 33:1,225-1,228. 